\title{
Effect of the mGluR5-NAM Basimglurant on Behavior in Adolescents and Adults with Fragile $X$ Syndrome in a Randomized, Double-Blind, Placebo-Controlled Trial: FragXis Phase 2 Results
}

\author{
Eriene A Youssef*, , Elizabeth Berry-Kravis ${ }^{2}$, Christian Czech $^{3}$, Randi J Hagerman ${ }^{4}$, David Hessl ${ }^{5}$, \\ Chin Y Wong ${ }^{6}$, Michael Rabbia ${ }^{7}$, Dennis Deptula ${ }^{8}$, Amy John ${ }^{9}$, Russell Kinch ${ }^{10}$, Philip Drewitt ${ }^{11}$, \\ Lothar Lindemann ${ }^{3}$, Moritz Marcinowski ${ }^{12}$, Rachel Langland ${ }^{13}$, Carsten Horn ${ }^{14}$, Paulo Fontoura ${ }^{15}$, \\ Luca Santarelli ${ }^{16}$, Jorge A Quiroz ${ }^{17}$ and FragXis Study Group
}

'Roche Pharmaceutical Research and Early Development, Neuroscience, Ophthalmology, and Rare Diseases, Roche Innovation Center New York, New York, NY, USA; ${ }^{2}$ Departments of Pediatrics, Neurological Sciences, and Biochemistry, Rush University Medical Center, Chicago, IL, USA; ${ }^{3}$ Roche Pharmaceutical Research and Early Development, Neuroscience, Ophthalmology, and Rare Diseases, Roche Innovation Center Basel, Basel, Switzerland; ${ }^{4}$ Medical Investigation of Neurodevelopmental Disorders (MIND) Institute and Department of Pediatrics, University of California Davis, School of Medicine, Sacramento, CA, USA; ${ }^{5}$ Medical Investigation of Neurodevelopmental Disorders (MIND) Institute and Department of Psychiatry and Behavioral Sciences, University of California Davis, School of Medicine, Sacramento, CA, USA; ${ }^{6}$ Genentech Research and Early Development, South San Francisco, CA, USA; ${ }^{7}$ Roche Product Development, Roche Innovation Center New York, New York, NY, USA; ${ }^{8}$ ImmunoBrain Check Ltd., Ness-Ziona, Israel; ${ }^{9}$ Gilead Sciences, Foster City, CA, USA; ${ }^{10}$ Eisai EMEA, Hatfield, UK; "'Roche Pharmaceutical Research and Early Development, Neuroscience, Ophthalmology, and Rare Diseases, Roche Innovation Center Welwyn, Welwyn, UK; ${ }^{12}$ Roche Diagnostics GmbH, Mannheim, Germany; ${ }^{13}$ Genomics \& Oncology Research, Roche Molecular Systems, Inc., Pleasanton, CA, USA; ${ }^{14}$ Roche Pharmaceutical Research and Early Development, Pharmaceutical Sciences, Roche Innovation Center Basel, Basel, Switzerland; ${ }^{15}$ Roche Neuroscience Product Development, Basel, Switzerland; ${ }^{6}$ Therachon, AG, Basel, Switzerland; ${ }^{17}$ Solid Biosciences, Cambridge, MA, USA

\begin{abstract}
Preclinical data suggest that inhibition of the metabotropic glutamate receptor 5 (mGluR5) receptor might hold therapeutic benefits in Fragile X syndrome (FXS). Treatment of Fmrl knockout mice with mGluR5-negative allosteric modulators (NAMs) has been reported to correct a broad range of phenotypes related to FXS. The early short-term clinical trials with mGluR5 NAMs, including basimglurant, assessing the effects in individuals with FXS, were supportive of further exploration in larger, well-controlled trials. We evaluated basimglurant, a potent and selective mGluR5 NAM, in a 12-week, double-blind, parallel-group study of 183 adults and adolescents (aged 14-50, mean 23.4 years) with FXS. Individuals with an FMR/ full mutation were randomized to placebo or one of two doses of basimglurant. The primary efficacy endpoint was the change from baseline in behavioral symptoms using the Anxiety Depression and Mood Scale (ADAMS) total score. All treatment arms showed marked behavioral improvements from baseline to week 12 with less improvement in the basimglurant $1.5 \mathrm{mg}$ arm than placebo; however, basimglurant $0.5 \mathrm{mg}$ was inferior to placebo in the ADAMs total score. Treatment with basimglurant was overall well-tolerated. A higher incidence of adverse events classified as psychiatric disorders were reported in patients treated with basimglurant, including three patients with hallucinations or psychosis. In this phase 2 clinical trial, basimglurant did not demonstrate improvement over placebo. Evaluation of the overall risk-benefit in younger patient populations is an important consideration for the design of potential further investigations of efficacy with this class of medications. Neuropsychopharmacology (2018) 43, 503-512; doi:I0.1038/npp.2017.177; published online 20 September 2017
\end{abstract}

\section{INTRODUCTION}

Promising preclinical results have supported the hypothesis that inhibition of the metabotropic glutamate receptor 5

*Correspondence: Dr EA Youssef, Roche Pharmaceutical Research and Early Development Neuroscience, Ophthalmology and Rare Diseases, Roche Innovation Center New York, 430 East 29th Street, New York, NY I0016, USA, Tel: +I 646 46I 5II7, Fax: +I 646 46I 5322, E-mail: eriene.wasef@roche.com

Received 13 March 2017; revised 9 August 2017; accepted 10 August 2017; accepted article preview online 17 August 2017
(mGluR5) may improve symptoms of Fragile X syndrome (FXS) (Bear et al, 2004; Hagerman et al, 2014). The ' $m G l u$ receptor theory of Fragile X' postulates that in the absence of the Fragile X Mental Retardation Protein (FMRP), an RNA binding protein that attenuates the translation of its target transcripts (Li et al, 2001), there is excessive mGluRdependent protein synthesis which underlies the pathogenesis of FXS (Bear et al, 2004; Huber et al, 2002). Reduction of mGluR5 activity by either genetic (Dolen et al, 2007) or pharmacological (Bhakar et al, 2012; Michalon et al, 2012) 
means in Fmr1 KO mice has achieved the correction of numerous FXS phenotypes, including biochemical, neuroanatomical, electrophysiological and synaptic plasticity alterations, learning and memory impairment, audiogenic seizures, and growth abnormalities. These data suggest that the FXS phenotype is not an irreversible result of altered brain development which collectively has prompted investigations of the therapeutic potential of mGluR5 negative allosteric modulators (NAMs) in humans.

In recent years, selective mGluR5 antagonists have been studied in individuals with FXS in short-term clinical trials. Fenobam (Porter et al, 2005), the first to be evaluated in a single-dose open-label study of 12 male and female adults with FXS (mean age 23.9 years), showed trends of improvement in a prepulse inhibition deficit relative to test-retest controls not receiving the drug (Berry-Kravis et al, 2009). Subsequently, a post-hoc analysis of a 12-week crossover-study with mavoglurant (AFQ056) (Vranesic et al, 2014) in 30 male adults (aged 18-35) with FXS described maladaptive behavior reduction in a subset of seven patients with full FMR1 methylation (Jacquemont et al, 2011). These behavioral effects were not replicated in subsequent 12-week, double-blind mavoglurant studies enrolling male and female adolescents and adults in the strata with either full or partial FMR1 methylation (BerryKravis et al, 2016), which were conducted in parallel to this basimglurant trial.

Basimglurant is a potent and selective mGluR5 NAM (Jaeschke et al, 2015; Lindemann et al, 2015). In acute and chronic rodent models of depression, basimglurant showed robust antidepressant-like activity, wakefulness-promoting effects and a consistent anxiolytic-like profile (Lindemann et al, 2015). Moreover, basimglurant $1.5 \mathrm{mg}$ showed an antidepressant effect across secondary endpoints in patients diagnosed with major depressive disorder, though the primary outcome was not met (Quiroz et al, 2016). Taken together with preclinical results from chronic treatment of Fmr1 knockout mice (Michalon et al, 2012) using CTEP (Lindemann et al, 2011), a close chemical analogue of basimglurant, these data were supportive of an initial evaluation of basimglurant in a 6-week, randomized, doubleblind, placebo-controlled, safety and exploratory efficacy study of 40 male and females with FXS (aged 18-49 years) treated with placebo, or basimglurant at daily doses of $0.1,0.5,1.0$, or $1.5 \mathrm{mg}$. In this trial, treatment with basimglurant was well tolerated and, though not powered to detect a difference, showed trends for clinical effects warranting further evaluation using the same measures in a larger sample size (unpublished data). Here, we report the results of the randomized, double-blind, placebo-controlled phase 2 investigation of the safety and efficacy on behavioral symptoms with basimglurant in adolescents and adults with FXS.

\section{MATERIALS AND METHODS}

\section{Patients}

Outpatients aged 14-50 with a confirmed FMR1 full mutation at screening were eligible to participate. Enrolled patients demonstrated a level of behavioral symptoms (Aberrant Behavior Checklist $(A B C)$ total $\geqslant 20$ ) as reported by caregivers and were at least 'mildly ill' on the Clinical
Global Impression-Severity scale $(C G I-S \geqslant 3$ ) based upon the clinician's overall assessment. The ABC entry score was selected to ensure both a minimum level of symptoms and adequate enrollment of females based upon the mean ABC total score in patients with FXS (Sansone et al, 2012). Stable doses of prescribed medications were permitted with the exception of medications with a glutamatergic or GABAergic mechanism of action. No new or changes to concomitant treatments were permitted from screening to the final visit. Adequate birth control was required for all patients during the course of the trial.

Patients were excluded if they had received treatment with another mGluR5 antagonist within 18 months prior to screening or participated in a prior basimglurant trial. Other exclusion criteria were any uncontrolled, unstable, clinically significant psychiatric or medical conditions other than FXS, including: seizures or a change in the anticonvulsant pharmacotherapy in the previous 6 months; concurrent symptoms or presumption of psychosis or euphoria; history of catatonia, hallucinations or delusional thoughts; or history of suicidal behaviors.

Either the patient or the parent/legal guardian provided informed consent or assent prior to participation.

\section{Study Design}

This phase 2, double-blind, randomized, placebo-controlled, 12-week study of two doses of basimglurant (Supplementary Figure 1) was conducted in accordance with the principles of the 'Declaration of Helsinki' and Good Clinical Practice. Approval of the study by the Independent Ethics Committee or Institutional Review Board for each investigative center was obtained before study start. An Independent Data Monitoring Committee was convened to review available unblinded safety data at regularly scheduled intervals.

After the screening period, patients underwent equal randomization to either basimglurant $0.5 \mathrm{mg}$, basimglurant $1.5 \mathrm{mg}$, or matching placebo using an interactive voice response system. Treatment allocation was stratified by sex and by age group (adolescents 14-17 years old $v s$ adults 18-50 years old) to ensure that approximately one-third of enrolled patients were adolescents. The blinded study medication was administered once daily in the morning with food. Compliance was assessed by a caregivercompleted medication diary as well as the return of all unused study medication at each visit.

After consulting with health authorities, the protocol was amended during study conduct to modify the primary efficacy endpoint from the Anxiety Depression and Mood Scale (ADAMS) social avoidance factor to ADAMS total score. This change occurred without unblinding the study and was not based upon blinded data review.

This clinical trial (FragXis, NP27936) is registered in www. clinicaltrials.gov with the identifier NCT01517698. FragXis was sponsored by Hoffmann La-Roche, Ltd, Switzerland (http://www.roche-trials.com).

\section{Assessments}

Baseline demographic and caregiver information were collected to better characterize enrolled patients including the Wechsler Intelligence Scale for Children-Fourth Edition 
(WISC-IV) and the Autism Diagnostic Observation Schedule (ADOS). A caregiver with knowledge of the patient's situation and level of impairment was identified upon enrollment of patients and required to complete certain rating scales. All identified caregivers watched a standardized rater training video at the screening visit.

Efficacy assessments at the clinic visits (occurring every 3 weeks) were to be completed by the same person for the study's duration. The primary efficacy outcome was the ADAMS total score, a 28-item caregiver-completed instrument assessing aspects of anxiety, social interaction, compulsiveness, communication, concentration, depression, and mood (Esbensen et al, 2003). Higher scores indicate more severe behavioral problems. The items are grouped into five factors representing core behaviors and symptoms for individuals with intellectual disability, including those with FXS.

For the secondary efficacy assessments, a number of caregiver and clinician rated scales were used at clinic visits to assess behaviors, functional skills, immediate memory, and overall symptoms. The ABC total and two factor score methods, based on a population of patients with intellectual disabilities (Aman et $a l, 1985$ ) and more recently in patients with FXS (Sansone et al, 2012), as well as the Social Responsiveness Scale (SRS) were used to measure symptoms (Constantino et al, 2003). Additionally, the caregiver provided a baseline description of the patient's most troubling symptom (MTS), including frequency, duration spent on it, and other salient consequences. Caregivers then evaluated this behavioral symptom using a Visual Analog Scale (VAS) every 6 weeks. For the analysis, each MTS description was coded using the MedDRA classification of terms.

Clinicians were asked to evaluate all aspects of the patient's behavior and cognitive function using both the CGI Severity of illness (CGI-S) and improvement (CGI-I) scales (Guy, 1976). The frequency of patients exhibiting clinical response was defined by at least $25 \%$ improvement in the ABC total score and a CGI-I score of 1 or 2 . The remaining secondary and exploratory assessments were conducted every 6 weeks. This included the Vineland Adaptive Behavior Scale (VABSII) with the exception of the maladaptive behavior domain (Sparrow et al, 2005), and the Repeatable Battery for the Assessment of Neuropsychological Status (RBANS; (Randolph et al, 1998)) List Learning and Story Memory subtests based on prior studies where the subtests of Immediate Memory were shown to be sufficiently reproducible in the FXS population (Berry-Kravis et al, 2006). Additionally, exploratory caregiver-reported outcomes were measured using the Caregiver Burden Inventory-Modified (Caserta et al, 1996).

The safety and tolerability of basimglurant was assessed at every clinic visit by monitoring vital signs, weight, Tanner staging (in adolescents at baseline and week 12), menstrual status (in females), clinical laboratory tests, and ECGs. Spontaneously reported AEs and a clinical assessment of suicidality were monitored weekly by phone calls or in clinic visits.

\section{Biomarkers Analysis}

A whole blood sample was taken from every patient at screening and analyzed via Southern Blot to confirm entry criteria. Additional whole blood samples were taken at baseline for analysis of DNA methylation status and CGG repeat size, FMR1 mRNA and FMRP analyses (see Supplementary Material).

\section{Statistical Analyses}

For the ADAMS total score, a closed testing procedure was utilized which first tested the overall hypothesis at the twosided significance level $\alpha=0.05$ using Dunnett's test, and then tested each active arm vs placebo separately only if the overall hypothesis $\mathrm{H} 0$ was rejected. The closed testing procedure has a two-sided maximum family-wise error rate of 0.05 ; therefore, no further adjustment for multiplicity was required.

For each continuous efficacy endpoint, analysis was performed using an MMRM model with the change from baseline in the endpoint as the dependent variable, treatment, visit, region, age group (adolescent $v s$ adult) and sex as independent effects, treatment-by-visit and age-by-sex interaction terms, and baseline value as the continuous covariate.

The sample size of 60 patients per group (a total of 180 patients for the three treatment groups) had been chosen to obtain a power of approximately $80 \%$ at a two-sided maximum, family-wise error rate of 0.05 in the testing procedure. An effect size of 0.60 in at least one dose group at week 12 (with an increasing treatment difference over the period), and an overall dropout rate of $15 \%$, were assumed.

The intent to treat (ITT) analysis population included all randomized patients who received at least one dose of the randomized study drug and was the primary analysis population for all analyses of primary and secondary clinical efficacy data. Subgroup analyses of the primary efficacy variable were performed as defined by stratification factors at randomization, clinically relevant baseline factors, and selected biomarker subpopulations (defined using the median biomarker values from the male patients) using an MMRM model.

\section{RESULTS}

\section{Patient Disposition and Demographics at Baseline}

A total of $185 \mathrm{FX}$ full mutation patients (151 male and 34 female) were randomized to basimglurant $0.5 \mathrm{mg}$, basimglurant $1.5 \mathrm{mg}$, or placebo at 39 centers in Argentina, Canada, Chile, France, Great Britain, Mexico, Spain, Sweden and the US between May 2012 and April 2014. Two patients randomized to the $0.5 \mathrm{mg}$ dose group withdrew from the study prior to receiving any study treatment. Therefore, a total of 183 patients received study treatment (ITT) and 167 completed the 12-week blinded treatment period. A higher proportion of patients discontinued from the 12-week treatment period in the basimglurant $1.5 \mathrm{mg}$ dose group $(16.1 \%)$ than the $0.5 \mathrm{mg}(8.6 \%)$ or placebo (1.6\%) groups, although the discontinuations related to adverse events (AE) were similar in both basimglurant 1.5 and $0.5 \mathrm{mg}$ dose groups (9.7 and 8.6\%, respectively; Supplementary Figure 2).

Patient demographics and baseline symptoms were generally well-matched for both the adolescent and adult subpopulations (Table 1). Most patients had fluent speech; nonverbal patients were not enrolled in the study. There were some imbalances in the characterization of autism 
Table I Demographics and Baseline Disease Characteristics

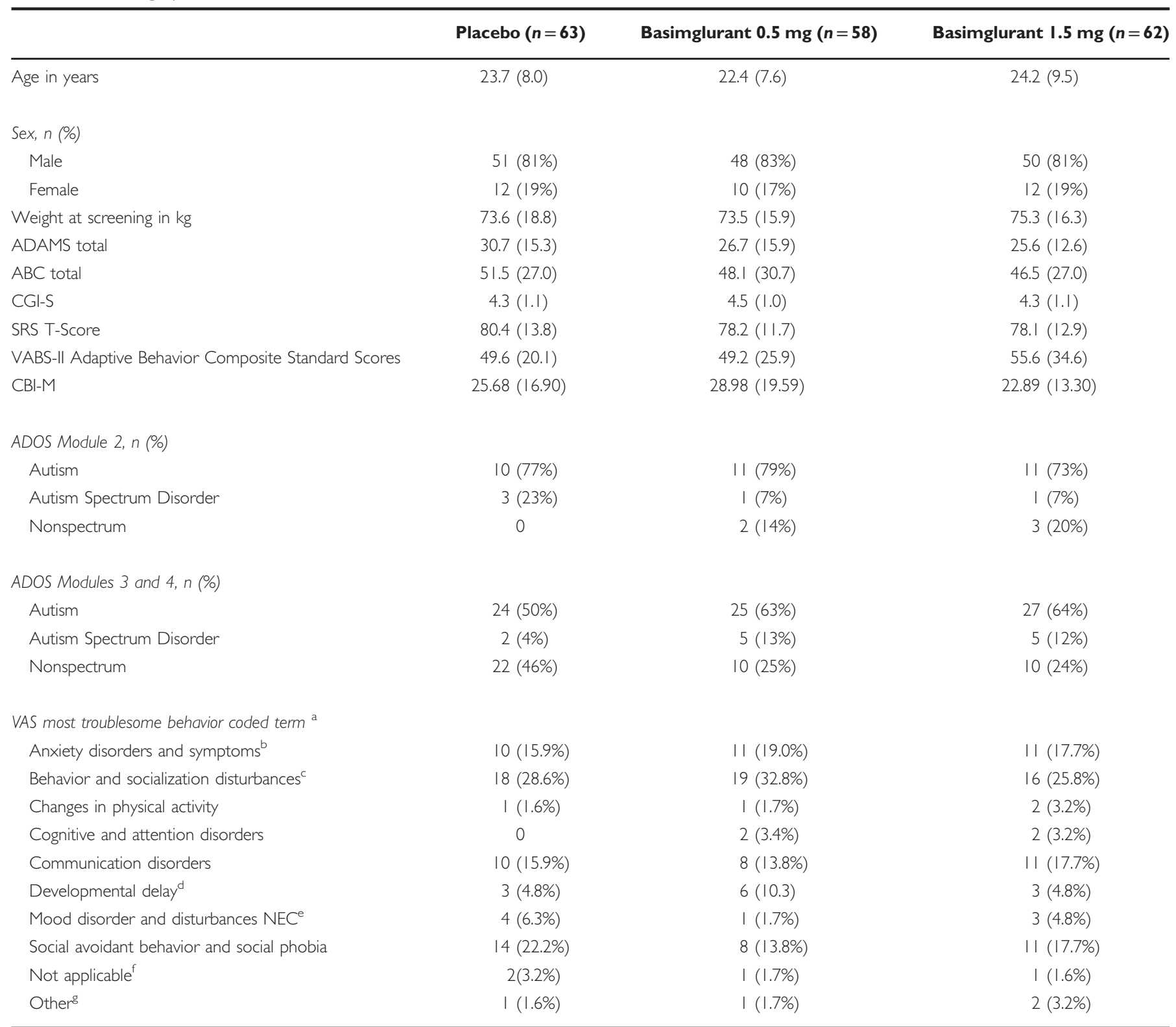

A higher ADAMS, ABC, CGI-S, SRS and CBI-M score indicates more severe behavioral symptoms. A lower VABS-II score indicates more impaired adaptive behavior. All data are presented as mean (SD) unless specified.

aMost troubling symptom coded term is the MedDRA Higher Level Group Term unless otherwise specified.

${ }^{\mathrm{b}}$ Anxiety disorders and symptoms excludes social phobia.

'Behavior and socialization disturbances was used in place of the Higher Level Group Term and includes impulsive behavior and sexually inappropriate behavior and excludes social avoidant behavior.

dDevelopmental delay was used in place of the Higher Level Group Term.

eMood disorders and disturbances NEC includes depression.

${ }^{f}$ Not applicable includes no specific behavior concern or assessment not completed.

'Other includes enuresis, perseveration, autism, and eating disorder symptom NOS.

spectrum disorder (ASD) across treatment arms, with more patients with fluent speech considered nonspectrum in the placebo group than in both groups treated with basimglurant (46 vs 25\%). For those patients with phrase speech, all patients randomized to placebo met autism spectrum disorder criteria as compared to approximately $83 \%$ of those randomized to basimglurant.

\section{Previous and Concurrent Diseases and Treatments}

The most frequent previous and concurrent conditions reported per the MedDRA classification system were the following psychiatric disorders: Anxiety (up to 27.0\%), attention deficit/hyperactivity disorder (up to 20.6\%), and aggression (up to $16.1 \%$; see Supplementary Table 1). The 
use of psychotropic medicine was similar across treatment groups, with the most common classes being CNS stimulants (up to 20.6\%), antipsychotic and antimanic agents (up to 25.9\%), selective serotonin re-uptake inhibitors (up to $27.0 \%$ ) and tetracyclines (ie minocycline, up to 10.3\%; see Supplementary Table 2).

\section{Caregiver Characteristics and Baseline Observations}

Nearly all caregivers were a parent of the patient (96\%), and $74 \%$ reported spending over $40 \mathrm{~h}$ each week interacting with the patient (see Supplementary Table 3). The common caregiver-reported MTS used for the VAS were anxiety disorders and symptoms, behavior and socialization disturbances, communication disorders and disturbances, and social avoidant behavior/social phobia (examples in Table 1). Additionally, the level of caregiver burden at baseline was similar across groups as assessed by the CBI-M (Table 1).

\section{Effect of Basimglurant on the ADAMs}

In the primary endpoint analysis for the ADAMS total change from baseline to week 12, both basimglurant treatment groups showed no improvement over placebo (Figure 1). In fact, significantly greater reductions from baseline were observed in the placebo group compared to the basimglurant $0.5 \mathrm{mg}$ group (difference from placebo $(90 \%$ confidence interval) of $4.43(1.43-7.43)$, adjusted $p=0.030)$ but not the basimglurant $1.5 \mathrm{mg}$ group (difference from placebo of $2.00(-1.00-5.00)$, adjusted $p=0.271)$ (Table 2$)$. ADAMS total score results were prospectively analyzed in separate subgroup analyses. In all analyses, basimglurant showed no improvement over placebo in any subgroups (Table 2).

\section{Effects of Basimglurant on Secondary Measures}

Similarly, in the analyses of the secondary endpoints, all treatment groups improved but basimglurant did not demonstrate any benefit over placebo at Week 12 in the ABC total and factor scores, SRS T-score, VAS, VABS-II Adaptive Behavior Composite standard score (Table 2) or ADAMS factor scores (Supplementary Table 4). Treatment with basimglurant did not show improvement over placebo on the CGI-S and CGI-I. Of note, placebo had a greater

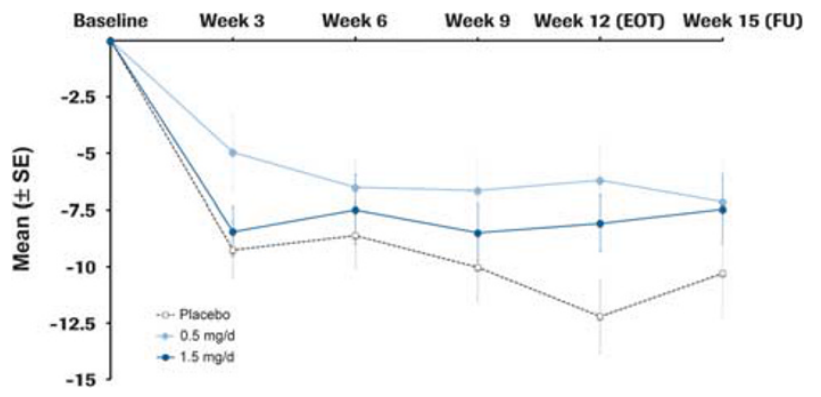

Figure I Change from baseline in ADAMS Total scores at each visit (ITT). A decrease in the ADAMS total score indicates improvement. Both basimglurant treatment groups showed no improvement over placebo. improvement over the basimglurant $0.5 \mathrm{mg}$ group in the CGI-I and a greater improvement over both basimglurant dose groups in the SRS T-Score $(p<0.05$, Table 2). Correspondingly, more responders at week 12 were in the placebo group (23.81\%) as compared to basimglurant $0.5 \mathrm{mg}$ $(13.79 \%, p=0.174)$ and $1.5 \mathrm{mg}(17.74 \%, p=0.510)$ groups (Table 2).

\section{Biomarker Subgroup Analysis of Study Patients}

Baseline measures for methylation status of the FMR1 gene, mRNA and FMRP showed considerable heterogeneity in the study population (Figure 2). Correlations were observed between FMR1 methylation status and mRNA levels (Pearson correlation coefficient $(r)$ of -0.74$)$, and between FMR1 methylation status and FMRP levels $(r=-0.64)$ but not between mRNA and FMRP concentrations $(r=0.39$; $p<0.001$ for all paired data sets).

The relationship of biomarker subgroups and the effects of basimglurant were also explored. Biomarker positive was defined by FMR1 methylation greater than $73.95 \%$ of the analyzed methylation sites, mRNA $\Delta C T$ count greater than 1.975 , or FMRP concentrations less than $0.146 \mathrm{pM}$. The analysis showed that both biomarker-positive and -negative subgroups did not differ significantly between placebo and basimglurant in the assessment of change from baseline to week 12 for the ADAMS total score (Table 2). In the FMR1 methylation negative $(<73.95 \%)$ subgroup, patients who were randomized to the placebo arm improved significantly $(p=0.019)$ compared to patients in the basimglurant $0.5 \mathrm{mg}$ dose arm. This improvement may be driven by the change in ADAMS total scores from the female patients in the placebo arm.

\section{Safety and Tolerability of Basimglurant}

Approximately two-thirds of patients (122 of 183) experienced at least one AE during the study. Of the most common AEs ( $>5 \%$ incidence; Table 3 ), those classified as psychiatric disorders had a higher incidence in patients treated with basimglurant $0.5 \mathrm{mg}$ (21 AEs in $24.1 \%$ of patients) and basimglurant $1.5 \mathrm{mg}$ ( $61 \mathrm{AEs}$ in $40.3 \%$ of patients) compared to those given placebo (12 AEs in $14.3 \%$ of patients). Most AEs were considered mild to moderate in severity. All of the severe AEs occurred in 4 adults in the basimglurant $1.5 \mathrm{mg}$ dose $(n=3)$ and $0.5 \mathrm{mg}(n=1)$ groups and were mainly psychiatric disorders. One serious adverse event of fecaloma (extreme form of fecal impaction) requiring overnight hospitalization was reported in the placebo group but the patient continued in the study.

A similar number of patients on basimglurant 0.5 and $1.5 \mathrm{mg}$ discontinued due to AEs with the most frequent events being psychiatric disorders (basimglurant $0.5 \mathrm{mg}$, $n=4(6.9 \%)$ and basimglurant $1.5 \mathrm{mg}, n=4(6.5 \%)$ vs placebo, $n=1(1.6 \%))$. Two adult male patients receiving basimglurant $1.5 \mathrm{mg}$ experienced hallucinations; one of the two events resolved during the study. One patient from the basimglurant $0.5 \mathrm{mg}$ group had an event of 'moderate psychotic disorder' which was resolving at the end of the study. For all three patients, the event occurred with or was preceded by adverse events of insomnia or poor sleep, and all 
Table 2 Change from Baseline at Week 12 for all Efficacy Endpoints

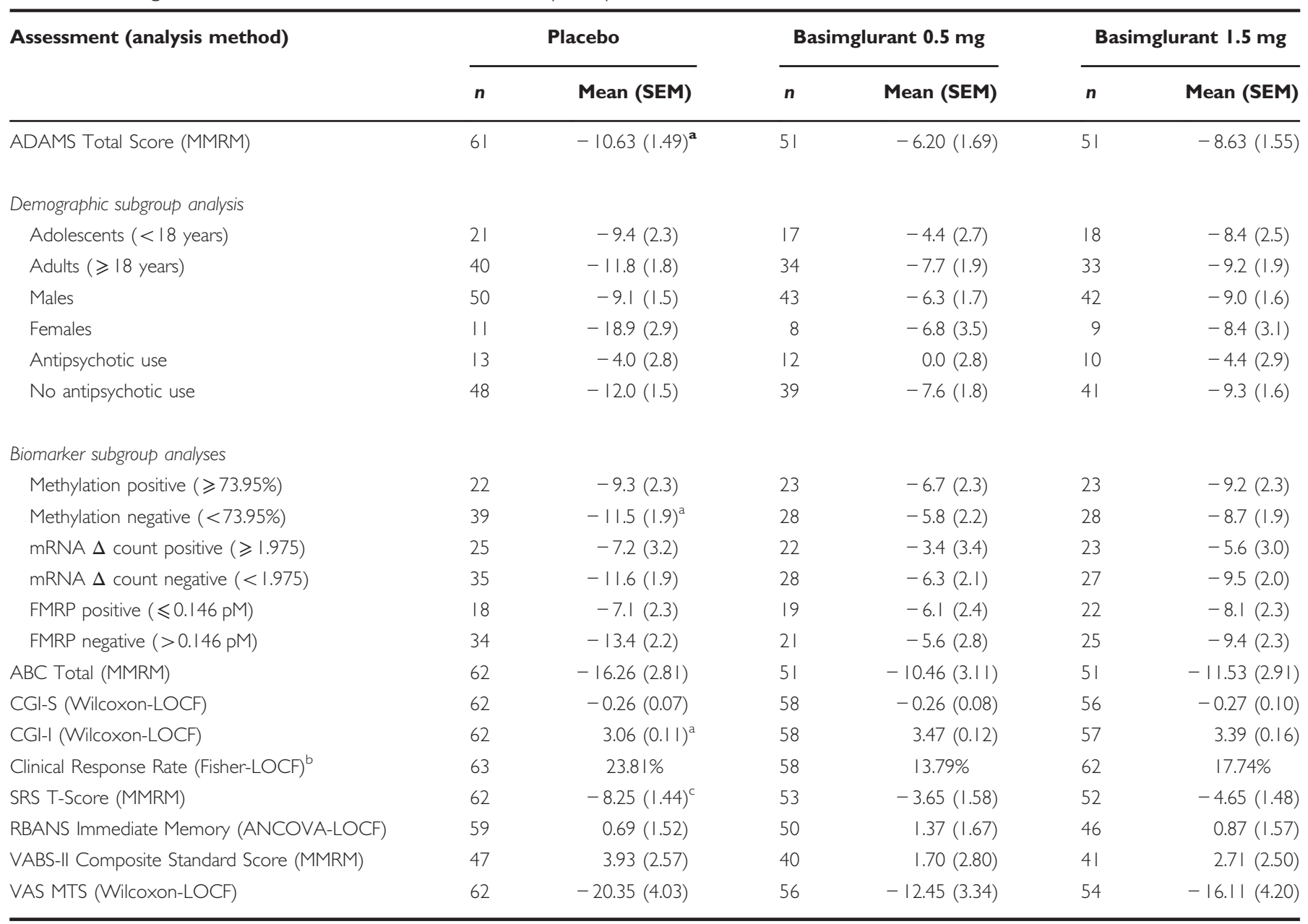

A decrease in ADAMS, ABC, CGI-S, CGI-I, SRS, and VAS scores indicates improvement. An increase in the RBANS and VABS-II score indicates improvement. Values are least square mean (SEM).

Analyses conducted were based upon the assessment and include Mixed Effect Model Repeated Measures (MMRM), Wilcoxon-Last Observation Carried Forward (LOCF), Fisher-LOCF, and analysis of covariance (ANCOVA)-LOCF, all with standard error of the mean (SEM).

a $p \leqslant 0.05$ compared to basimglurant $0.5 \mathrm{mg}$.

${ }^{b}$ Clinical response defined as a composite of improvement in ABC Total Score of $25 \%$ or more and of a CGI-I score of either I or 2.

$c_{p} \leqslant 0.05$ compared to basimglurant 0.5 and $1.5 \mathrm{mg}$.

three patients were discontinued from study treatment immediately after the AE was observed.

Overall, no clinically relevant changes in mean laboratory parameters, vital signs, ECG, menstrual status (in females), or physical exams including weight and sexual maturation (Tanner staging and hormones related to sexual maturation in adolescents) indicative of any treatment-emergent effect were noted during the study.

\section{DISCUSSION}

This phase 2 study was the first to evaluate the efficacy of basimglurant, a potent and selective mGluR5 NAM, in adolescents and adults with FXS. The primary endpoint, the ADAMS total, measured social avoidance, manic/hyperactive behavior and other behavioral symptoms, with the largest improvement in the placebo group, followed by improvement in the basimglurant 0.5 and $1.5 \mathrm{mg}$ arms, respectively. Additionally, analyses of the secondary efficacy endpoints evaluating several behavioral components, functioning, and overall severity of illness showed similar directional improvements for placebo over the active treatment groups. The replication of these negative findings with those seen in the 12-week, double-blind mavoglurant studies, though conducted in parallel with this basimglurant study, is salient given several design differences including their implementation of a placebo run-in phase, stratification by methylation status and up-titration dosing strategy (Berry-Kravis et al, 2016).

The lack of a measureable therapeutic effect in this study has several potential contributing factors, including endpoint selection, study design and implementation, placebo response, subgroup heterogeneity and ultimately the translatability of preclinical findings into a clinical population. The 

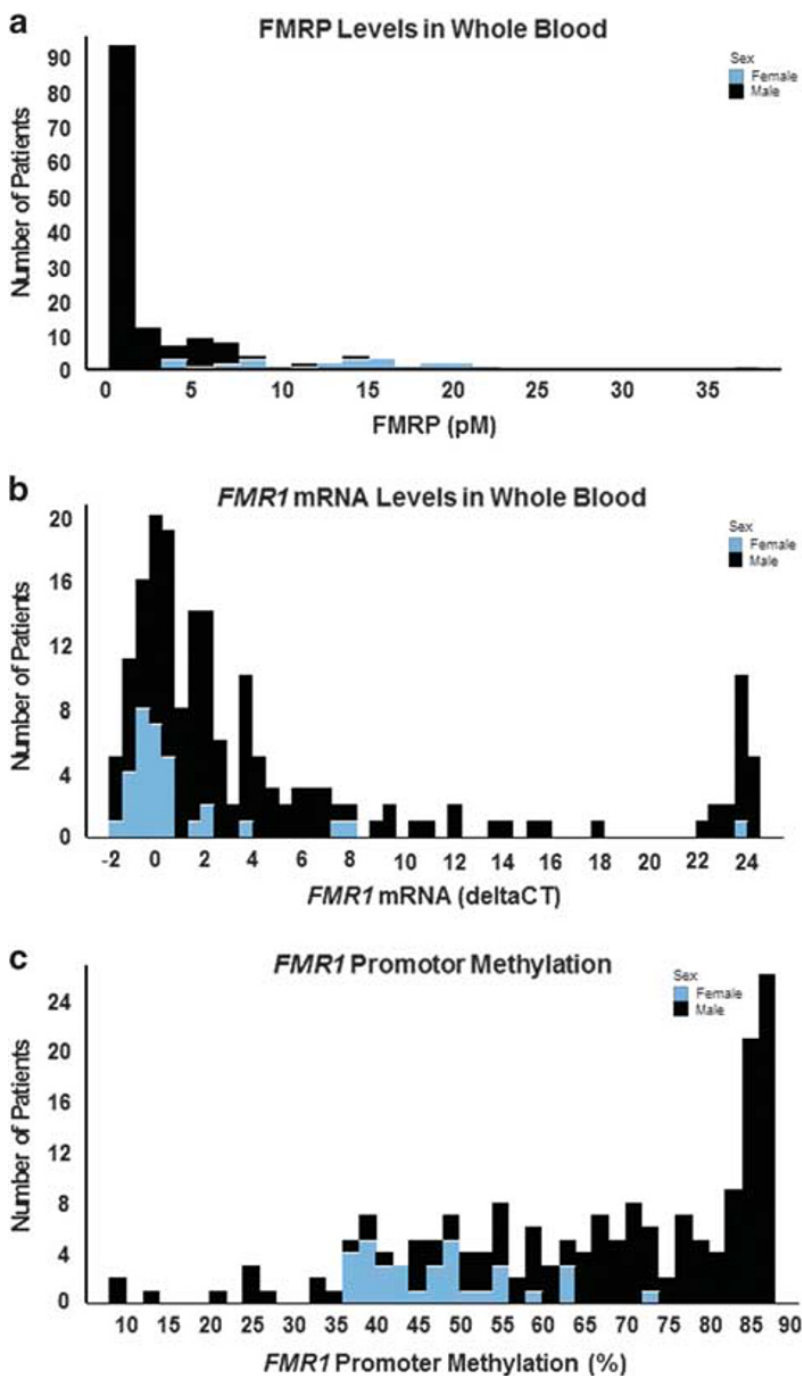

Figure 2 Biomarker analysis of FMRI promoter methylation, FMRI mRNA and FMRP in study patients. The figure shows the frequency distribution of biomarker data. Data of patients were distributed over 50 bins and frequency of appearance is depicted on the $\mathrm{Y}$-axis. Male-derived samples are in solid black and Female in blue bars. (a) Levels of FMRP in whole blood in pM. Most of the male patients had no detectable levels of FMRP in the blood (0 pM). (b) Levels of FMR I mRNA expressed as delta $C T$ values. Note that delta $C t$ values over 6 are not considered to represent quantifiable levels of mRNA but rather unspecific noise as judged by the $C P$ curves. (c) Methylation of the FMRI promoter expressed in percent methylation of analyzed methylation sites.

selection of a primary efficacy endpoint in a disorder with no prior clinical precedence for specific behaviors or symptoms that may be modified by a pharmacological intervention has proven extremely difficult. The Fragile X Outcome Measures Working Group, an NIH-supported collaboration, concluded that no single endpoint or set of endpoints could be identified that met all criteria as an optimal measure for studies investigating a treatment effect (Berry-Kravis et al, 2013). Notwithstanding, promising outcome measurements included the ADAMS and $\mathrm{ABC}$, which have some overlap in their underlying behavioral construct, SRS, and RBANS; all of which were explored in this study. Though the ABC scale has some regulatory approval precedence in autism and was
Table 3 Adverse Events with an Incidence of $\geqslant 5 \%$ in at Least One Treatment Arm

\begin{tabular}{|c|c|c|c|}
\hline & $\begin{array}{c}\text { Placebo } \\
(n=63)\end{array}$ & $\begin{array}{l}\text { Basimglurant } \\
0.5 \mathrm{mg}(n=58)\end{array}$ & $\begin{array}{l}\text { Basimglurant } \\
1.5 \mathrm{mg}(n=62)\end{array}$ \\
\hline $\begin{array}{l}\text { Overall total } \\
\text { number of AEs }\end{array}$ & 112 & 96 & 155 \\
\hline $\begin{array}{l}\text { Total patients with } \\
\text { at least one } A E, n \\
\text { (\%) }\end{array}$ & 40 (63.5\%) & 37 (63.8\%) & 45 (72.6\%) \\
\hline Nasopharyngitis & II (I7.5\%) & $9(15.5 \%)$ & $6(9.7 \%)$ \\
\hline Headache & 10 (I5.9\%) & $4(6.9 \%)$ & $10(16.1 \%)$ \\
\hline Vomiting & 5 (7.9\%) & $3(5.2 \%)$ & $7(11.3 \%)$ \\
\hline $\begin{array}{l}\text { Upper respiratory } \\
\text { tract infection }\end{array}$ & $4(6.3 \%)$ & I (1.7\%) & $6(9.7 \%)$ \\
\hline Anxiety & I (1.6\%) & $2(3.4 \%)$ & $6(9.7 \%)$ \\
\hline Aggression & I (1.6\%) & $5(8.6 \%)$ & $5(8.1 \%)$ \\
\hline Insomnia & I (I.6\%) & 0 & $5(8.1 \%)$ \\
\hline Diarrhea & $3(4.8 \%)$ & $4(6.9 \%)$ & $2(3.2 \%)$ \\
\hline $\begin{array}{l}\text { Upper abdominal } \\
\text { pain }\end{array}$ & $4(6.3 \%)$ & $2(3.4 \%)$ & 0 \\
\hline Agitation & $2(3.2 \%)$ & 0 & $4(6.5 \%)$ \\
\hline Dizziness & I (I.6\%) & I (1.7\%) & $4(6.5 \%)$ \\
\hline Irritability & I (I.6\%) & $3(5.2 \%)$ & $3(4.8 \%)$ \\
\hline
\end{tabular}

All adverse events (MedDRA preferred term) were reported by the safety population during the study treatment and follow-up periods. Multiple occurrences of the same $A E$ in an individual were counted only once. For frequency counts in the 'Total number of AEs' row, multiple occurrences of the same AE in an individual are counted separately. The safety population consisted of all patients who had received at least one dose of study medication.

selected as the primary measure in both mavoglurant and arbaclofen trials in FXS, we selected the ADAMS total as the primary outcome measure for this study based on both the prominence of social anxiety, hyperactivity and moodrelated symptoms in the phenotype of patients with FXS, as well as trends of improvement observed in our initial study in adults with the disorder. Of note, our study data are consistent with the negative mavoglurant results in that no difference from placebo was detected on the $A B C$ total or factors, CGI-I, and SRS total score. It is still possible that the scope of the assessments used were not comprehensive enough to detect early treatment effects, especially since behavioral patterns are typically developed during the lifetime of an individual based upon environmental influences. Therefore future studies should also place an emphasis on novel, or more sensitive endpoints capturing relevant improvements in core domains of FXS, including cognition. In particular, combining pharmacologic interventions with cognitive-behavioral therapies in patients with FXS may elicit broader responses that could be captured by these or alternative endpoints.

Several factors in the protocol design and data analysis were implemented to minimize variability, subjectivity, and potential placebo effect. The primary outcome and behavioral entry criterion (ADAMS and ABC total score, respectively) were selected to be different with the objective of minimizing baseline score inflation. Moreover, selected outcome 
measures were assessed by the caregiver (ADAMS, ABC, SRS, VAS) and clinician (CGI-S, CGI-I, RBANS, VABS-II) to capture potential improvement irrespective of the observer. Lastly, the same rater was required to conduct both the baseline and week 12 assessments, and where this did not occur, the per protocol analysis removed patient data with protocol violations. Despite these measures, none of these analyses altered the overall study results.

In this trial, all treatment arms improved, with patients in the basimglurant groups having less improvement than placebo. These changes, including the improvement in the placebo arm, may be at least partially explained by the higher frequency of interactions between patients and caregivers with the research staff during the study (Rutherford et al, 2011) or a degree of expectation bias, as cited in secretin treatment trials in individuals with autism (Volkmar, 1999) and suggested based upon the substantial improvements during the placebo run-in phase in the mavoglurant trials (Berry-Kravis et al, 2016). Nevertheless, the larger placebo improvement cannot entirely account for the results observed, and consideration should be given to the relatively smaller improvement observed in the basimglurant groups, which could be better explained by the level of behaviorally based adverse events, such as anxiety, aggression, agitation, and irritability, associated with the active treatment arms.

Pre-specified subgroup exploratory analyses including the stratification factors for age and sex were performed, with similar negative results. Based upon the neurodevelopmental nature of FXS and the mechanism of action of basimglurant it has been hypothesized that mGluR5 treatment in younger patients may help reverse deficits and prevent further insult caused by the lack of FMRP during brain development and maturation (Krueger and Bear, 2011). In our analysis which was divided by age (adolescents 14-17 and adults 18-50 years), no improvement over placebo was seen in either subgroup. Nonetheless, it is still possible that pharmacological interventions might be more efficacious at very early ages, when a larger degree of neuronal plasticity-related development is still occurring. Owing to the different phenotypic presentation across sexes, we also analyzed the treatment effect in both subpopulations. In this study, no sex differences in clinical responses were detected although the small number of females enrolled makes this finding inconclusive. Additionally, the ADOS was used as a demographic parameter for ASD severity, but given the imbalance of ASD across treatment arms, a subgroup analysis was not conducted. Based on the scope of subgroup analyses and the overall low proportion of responders (ABC and CGI composite) that remained higher in the placebo group than either basimglurant group, the overall interpretation of the results would not be anticipated to be different.

It has been previously reported in a small subgroup of patients that expression of FMR1 mRNA and methylation of the promoter region of the FMR1 gene may influence the response to mGluR5 NAM treatment (Jacquemont et al, 2011). We could not confirm this finding by analyzing FMR1 methylation, FMR1 mRNA, and FMRP levels in whole blood samples and performing the corresponding population subgroup analyses using the mean of the distribution for all three biomarker parameters. Correlations between FMR1 methylation and FMR1 mRNA levels, as well as FMR1 methylation and FMRP levels, however, confirm the biological validity of the biomarkers employed. While the mavoglurant phase 2 trials stratified individuals based on the extent of FMR1 methylation, the definition of complete and partial methylation was not provided to allow comparison with our biomarker analysis. Nevertheless, our exploratory subgroup analyses did not find any biomarker to be predictive of basimglurant treatment response and confirm the negative mavoglurant results (Berry-Kravis et al, 2016).

The results in this study contrast the preclinical data obtained with mGluR5 antagonists in Fmr1 KO mice. While the Fmr1 KO mice replicate the primary molecular determinant of FXS, that is, the lack of FMRP expression, they fall short of replicating the human disease in its full complexity, especially with respect to DNA methylation, $\mathrm{X}$-chromosomal and somatic mosaicism, as well as modifier genes. Nonetheless, given the breadth of phenotypes corrected with different mGlu5 NAM's in Fmr1 KO mice, and consistent results obtained from multiple laboratories, the complete lack of translation of the preclinical findings to the clinical outcomes does warrant further investigation (Scharf et al, 2015).

In this phase 2 clinical trial, basimglurant was found to be ineffective in the treatment of adults and adolescents with FXS relative to placebo. Consistent with other basimglurant studies, treatment at doses of 0.5 and $1.5 \mathrm{mg}$ once a day was generally well tolerated; however, a higher incidence of adverse events classified as psychiatric disorders were reported in patients treated with basimglurant compared to those receiving placebo. It is possible that longer treatment durations utilizing more sensitive outcome measures and/or focusing on cognitive and learning paradigms in a younger group of individuals may detect previously unnoticed treatment effects of mGluR5 NAM's in FXS patients.

\section{FUNDING AND DISCLOSURE}

Dr Berry-Kravis has received research funding from NIH, CDC, NCATS, the John Merck Fund, the FRAXA Research Foundation, the National Fragile X Foundation, the Hayley Koujaian and Samantha Berns NPC Research Fund and has received funding from Seaside Therapeutics, Novartis, Roche, Alcobra, Neuren, Cydan, Fulcrum, Ovid, GW and Neurotrope Pharmaceuticals to consult on trial design or development strategies and/or conduct clinical trials in FXS, from Vtesse to conduct clinical trials in NP-C, and from Asuragen Inc to develop testing standards for FMR1 testing. Dr Hagerman has consulted with Roche and received investigator payments and also consulted with Zynerba, Novartis, Alcobra, and Neuren on previous studies in fragile $\mathrm{X}$ syndrome. Dr Hessl has been a paid consultant for Roche. Drs Youssef, Czech, Wong, Lindemann, Marcinowski, Horn, and Fontoura as well as Mr Drewitt, Mr Rabbia, and Ms. Langland are employees of the Roche Group and as such may be eligible for stock and stock options. Drs Deptula, Santarelli, and Quiroz and Mr Kinch were employees of the Roche Group and as such may be eligible for stock and stock options. Dr John was an employee of Rutgers University, through a fellowship grant from Hoffmann La-Roche. Roche 
used internal developed rare reagents for the biomarker assays that are not commercially available.

\section{ACKNOWLEDGMENTS}

We are grateful to the patients, their families, and volunteers from the local FXS associations for their support and participation in this study. We thank the following principal investigators who along with their site staff conducted this study at their investigational sites: L. Alba, C. Ayuso, E. Balaguer, J. Berg, E. Berry-Kravis, W. Brown, J. ClaytonSmith, F. Corbin, L. Craft, V. Des Portes, C. Erickson, G. Feldman, J. Frazier, J. Fuentes, B. Gallardo, C. Gillberg, E. Guillén-Navarro, R. Hagerman, S. Hatti, I. Hernández Otero, M. Johnston, S. Joss, B. King, A. Kolevzon, A. Lachiewicz, D. Lacombe, P. Lapunzina, J. Malagon Valdez, A. Masurel, P. Mazzetti Solar, D. McBrien, R. Melmed, F. O’Neil, C. Paribello, C. Passalacqua, A. Pugin, A. Reynolds, K. Sanders, P. Sarda, E. Seminara, S. Sigaudy, A. Stanfield, A. Strydom, J. Tomasovic, A. Toutain, D. Treadwell-Deering, S. Turnacioglu, J. Visootsak, C. Waisburg.

We would like to thank Will Spooren for his dedicated scientific input and his strategic contributions which were essential for the initiation of the Fragile X program at Roche. We would also like to express our sincere appreciation to our colleagues, Ludger Banken and Riorge Thomas, for their contributions to the statistical programming and analysis on this study. We would like to further thank Priscilla Moonsamy and Michael Gerg for their contributions to the biomarker assay development and Laura Cristea for her support in the study conduct and operations.

\section{REFERENCES}

Aman MG, Singh NN, Stewart AW, Field CJ (1985). The aberrant behavior checklist: a behavior rating scale for the assessment of treatment effects. Am J Ment Defic 89: 485-491.

Bear MF, Huber KM, Warren ST (2004). The mGluR theory of fragile X mental retardation. Trends Neurosci 27: 370-377.

Berry-Kravis E, Des Portes V, Hagerman R, Jacquemont S, Charles $\mathrm{P}$, Visootsak J et al (2016). Mavoglurant in fragile X syndrome: results of two randomized, double-blind, placebocontrolled trials. Sci Transl Med 8: 321 ra325.

Berry-Kravis E, Hessl D, Abbeduto L, Reiss AL, Beckel-Mitchener A, Urv TK (2013). Outcome measures for clinical trials in fragile X syndrome. J Dev Behav Pediatr 34: 508-522.

Berry-Kravis E, Hessl D, Coffey S, Hervey C, Schneider A, Yuhas J et al (2009). A pilot open label, single dose trial of fenobam in adults with fragile X syndrome. J Med Genet 46: 266-271.

Berry-Kravis E, Krause SE, Block SS, Guter S, Wuu J, Leurgans S et al (2006). Effect of CX516, an AMPA-modulating compound, on cognition and behavior in fragile $X$ syndrome: a controlled trial. J Child Adol Psychop 16: 525-540.

Bhakar AL, Dolen G, Bear MF (2012). The pathophysiology of fragile X (and what it teaches us about synapses). Annu Rev Neurosci 35: 417-443.

Caserta MS, Lund DA, Wright SD (1996). Exploring the Caregiver Burden Inventory (CBI): further evidence for a multidimensional view of burden. Int J Aging Hum Dev 43: 21-34.

Constantino JN, Davis SA, Todd RD, Schindler MK, Gross MM, Brophy SL et al (2003). Validation of a brief quantitative measure of autistic traits: comparison of the social responsiveness scale with the autism diagnostic interview-revised. J Autism Dev Disord 33: 427-433.
Dolen G, Osterweil E, Rao BS, Smith GB, Auerbach BD, Chattarji S et al (2007). Correction of fragile X syndrome in mice. Neuron 56: 955-962.

Esbensen AJ, Rojahn J, Aman MG, Ruedrich S (2003). Reliability and validity of an assessment instrument for anxiety, depression, and mood among individuals with mental retardation. J Autism Dev Disord 33: 617-629.

Guy W (1976). ECDEU Assessment Manual for Psychopharmacology. U.S. Dept. of Health, Education, and Welfare, Public Health Service, Alcohol, Drug Abuse, and Mental Health Administration, National Institute of Mental Health, Psychopharmacology Research Branch, Division of Extramural Research Programs: Rockville, Maryland.

Hagerman RJ, Des-Portes V, Gasparini F, Jacquemont S, GomezMancilla B (2014). Translating molecular advances in fragile $X$ syndrome into therapy: a review. J Clin Psychiatry 75: e294-e307.

Huber KM, Gallagher SM, Warren ST, Bear MF (2002). Altered synaptic plasticity in a mouse model of fragile $\mathrm{X}$ mental retardation. Proc Natl Acad Sci USA 99: 7746-7750.

Jacquemont S, Curie A, des Portes V, Torrioli MG, Berry-Kravis E, Hagerman RJ et al (2011). Epigenetic modification of the FMR1 gene in fragile $\mathrm{X}$ syndrome is associated with differential response to the mGluR5 antagonist AFQ056. Sci Transl Med 3: 64ra61.

Jaeschke G, Kolczewski S, Spooren W, Vieira E, Bitter-Stoll N, Boissin $\mathrm{P}$ et al (2015). Metabotropic glutamate receptor 5 negative allosteric modulators: discovery of 2-chloro-4-[1-(4-fluorophenyl)-2,5-dimethyl-1H-imidazol-4-ylethynyl]pyridine (Basimglurant, RO4917523), a promising novel medicine for psychiatric diseases. J med chem 58: 1358-1371.

Krueger DD, Bear MF (2011). Toward fulfilling the promise of molecular medicine in fragile X syndrome. Annu Rev Med 62: 411-429.

Li Z, Zhang Y, Ku L, Wilkinson KD, Warren ST, Feng Y (2001). The fragile $\mathrm{X}$ mental retardation protein inhibits translation via interacting with mRNA. Nucleic Acids Res 29: 2276-2283.

Lindemann L, Jaeschke G, Michalon A, Vieira E, Honer M, Spooren $\mathrm{W}$ et al (2011). CTEP: a novel, potent, long-acting, and orally bioavailable metabotropic glutamate receptor 5 inhibitor. $J$ Pharmacol Exp Ther 339: 474-486.

Lindemann L, Porter RH, Scharf SH, Kuennecke B, Bruns A, von Kienlin $M$ et al (2015). Pharmacology of basimglurant (RO4917523, RG7090), a unique metabotropic glutamate receptor 5 negative allosteric modulator in clinical development for depression. J Pharmacol Exp Ther 353: 213-233.

Michalon A, Sidorov M, Ballard TM, Ozmen L, Spooren W, Wettstein JG et al (2012). Chronic pharmacological mGlu5 inhibition corrects fragile $X$ in adult mice. Neuron 74: 49-56.

Porter RH, Jaeschke G, Spooren W, Ballard TM, Buttelmann B, Kolczewski S et al (2005). Fenobam: a clinically validated nonbenzodiazepine anxiolytic is a potent, selective, and noncompetitive mGlu5 receptor antagonist with inverse agonist activity. J Pharmacol Exp Ther 315: 711-721.

Quiroz JA, Tamburri P, Deptula D, Banken L, Beyer U, Rabbia M et al (2016). Efficacy and safety of basimglurant as adjunctive therapy for major depression: a randomized clinical trial. JAMA Psychiatr 73: 675-684.

Randolph C, Tierney MC, Mohr E, Chase TN (1998). The Repeatable Battery for the Assessment of Neuropsychological Status (RBANS): preliminary clinical validity. I Clin Exp Neuropsychol 20: 310-319.

Rutherford BR, Sneed JR, Tandler JM, Rindskopf D, Peterson BS, Roose SP (2011). Deconstructing pediatric depression trials: an analysis of the effects of expectancy and therapeutic contact. J Am Acad Child Adolesc Psychiatry 50: 782-795.

Sansone SM, Widaman KF, Hall SS, Reiss AL, Lightbody A, Kaufmann WE et al (2012). Psychometric study of the Aberrant Behavior Checklist in Fragile X Syndrome and implications for targeted treatment. J Autism Dev Disord 42: 1377-1392. 
Scharf SH, Jaeschke G, Wettstein JG, Lindemann L (2015). Metabotropic glutamate receptor 5 as drug target for Fragile $\mathrm{X}$ syndrome. Curr Opin Pharmacol 20C: 124-134.

Sparrow SS, Cicchetti DV, Balla DA (2005). Vineland Adaptive Behavior Scales, 2nd edn. The Psychological Corporation: San Antonio.

Volkmar FR (1999). Lessons from secretin. N Engl J Med 341: $1842-1844$.

Vranesic I, Ofner S, Flor PJ, Bilbe G, Bouhelal R, Enz A et al (2014). AFQ056/mavoglurant, a novel clinically effective mGluR5 antagonist: identification, SAR and pharmacological characterization. Bioorg Med Chem 22: 5790-5803.
(1) (-) $\Theta$ This work is licensed under a Creative Commons Attribution-NonCommercial-NoDerivs

International License. The images or other third party material in this article are included in the article's Creative Commons license, unless indicated otherwise in the credit line; if the material is not included under the Creative Commons license, users will need to obtain permission from the license holder to reproduce the material. To view a copy of this license, visit http://creativecommons.org/licenses/by-nc-nd/4.0/

(C) The Author(s) 2018

Supplementary Information accompanies the paper on the Neuropsychopharmacology website (http://www.nature.com/npp) 